\title{
Climate Risk Screening of Development Portfolios and Programmes
}

\section{Thomas Tanner}

\author{
1 Adapting development cooperation to climate \\ change \\ Responding to the impact of climate variability and \\ change on poverty, development organisations \\ increasingly acknowledge that climate change poses a \\ strategic risk to its core poverty reduction aims and \\ the achievement of the Millennium Development \\ Goals (MDGs) (ADB et al. 2003; DFID 2006; UNDP \\ 2007). For development cooperation donor agencies, \\ climate change also poses a fiduciary risk by potentially \\ compromising the effectiveness of the investments of \\ public funds in poverty reduction around the world. ${ }^{1}$ \\ These risks include direct risks of damages from \\ climate hazards to specific programme investments, \\ the risk of underperformance of the investment due \\ to climate change impacts (van Aalst 2006). In \\ addition, there are risks that poverty reduction \\ activities may in fact inadvertently lead to increases in \\ vulnerability, known as 'maladaptation', for example by
}

encouraging settlement in hazardous locations or altering natural protection afforded by ecosystems such as mangroves (Agrawala 2005; Adger et al. 2001).

A growing awareness of potential and existing climate risks to poverty reduction has underpinned a major drive for adaptation, and:
There is now also significant high-level policy endorsement within donor agencies and [International Finance Institutions] IFls for the need to integrate adaptation into development co-operation activities.
(Gigli and Agrawala 2007: 9)

A range of donor and international policy commitments are now underpinning a drive to address the negative impacts of climate change on poverty reduction (Table 1). While these aim to build

Table 1 Examples of policy commitments for integrating adaptation and development assistance

\begin{tabular}{ll}
\hline Policy commitments & Reference \\
\hline $\begin{array}{l}\text { Vulnerability and Adaptation Resource Group (VARG): Poverty and Climate Change: } \\
\text { Reducing the Vulnerability of the Poor Through Adaptation }\end{array}$ & ADB et al. (2003) \\
$\begin{array}{l}\text { European Union: Strategy and Action Plan on Climate Change in the Context of } \\
\text { Development Cooperation }\end{array}$ & EC (2004) \\
G8: Gleneagles Plan of Action; Hokkaido Toyako Summit Leaders Declaration & G8 $(2005,2008)$ \\
Asian Development Bank: Climate Proofing: A Risk-based Approach to Adaptation & ADB $(2005)$ \\
$\begin{array}{l}\text { OECD: Ministerial Declaration on Integrating Climate Change Adaptation into } \\
\text { Development Co-operation }\end{array}$ & OECD (2006) \\
UK International Development White Paper: Eliminating World Poverty: Making & DFID (2006) \\
Governance Work for the Poor &
\end{tabular}

IDS Bulletin Volume 39 Number 4 September 2008 (c) Institute of Development Studies 
the awareness and capacity of a wider range of development actors to factor climate change impacts into their operations, a key managerial response of development agencies has been to integrate, or mainstream, adaptation within their programmes as a risk management strategy.

In turn, these policy commitments have been influential in stimulating a burgeoning variety of tools and methods to improve decision-making to reduce risks and avail opportunities associated with climate variability and change. Tanner and Guenther (2007) provide a summary of some of the tools developed in the context of development assistance, and the OECD is currently preparing guidance material on integrating adaptation into development cooperation. A wider discussion and collation of vulnerability and adaptation tools and methods is also now a focus area under the Nairobi Work Programme under the UN Framework Convention on Climate Change (UNFCCC) (IISD 2008). Such tools range from climate data providers, through methodological guidance for entry points and steps in the adaptation process, to platforms for exchanging information resources, tools and reflection.

\section{Climate risk screening of development portfolios and programmes}

Drawing on much of this tool development, the screening of donor programme portfolios has emerged as one of the dominant methods to the integration of climate change adaptation into development cooperation (Klein et al. 2007). Such screening approaches build on lessons from the mainstreaming of other cross-cutting issues such as gender and HIV/AIDS into development activities, and particularly from environmental screening and strategic environment assessment processes. This article presents lessons from an example of portfolio-based climate risk screening to integrate adaptation and disaster risk reduction into poverty reduction programmes portfolio undertaken in partnership with the UK Department for International Development (DFID) (Tanner 2008).

Climate risk screening is defined in the context of propoor adaptation as:

The systematic evaluation of risks associated with climate variability and change to poverty reduction activities, and the development of effective, efficient and equitable adaptation options to reduce risks and harness opportunities for poverty reduction.

Using a risk management framework, such screening aims to examine the exposure of development investments to current and future climate risks, to assess the extent to which such investments already consider and manage such risks, and evaluate potential additional measures to address risks. While not undertaken comprehensively in the example shown in this article, at a more advanced level, such risk screening could also examine the risks and opportunities from climate change mitigation response measures or adaptation constraints and opportunities from carbon markets and a move to low carbon energy pathways.

Representing a managerial response to a changing climate, the risk management framework is increasingly being used to frame development approaches to adaptation (Burton and van Aalst 2004; ADB 2005; van Aalst 2006; Hellmuth et al. 2007). Climate risk management frames adaptation as a learning process constituting a spectrum of activities, some related to broader vulnerability reduction and some to more climate-specific impacts (Tanner and Mitchell, this IDS Bulletin, 'Entrenchment or Enhancement'; McGray et al. 2007). It is underpinned by an acknowledgement that the basis for adapting to the future climate lies in improving the ability to cope with existing climate variations, requiring integration with disaster risk reduction practices and institutions (Lemos and Tompkins, this IDS Bulletin).

In light of uncertainty over future climate change, risk management responses need to be informed by advances in climate science, and remain robust so that they are able to cope with a range of future scenarios. This requires integration of best available climate science and impacts, including attention to short-term seasonal forecasting, medium-term decadal forecasting, and longer-term climate projections (Wilby 2007). At the same time, information on hydro-meteorological and ecosystem impacts of climate change are complemented by social vulnerability information to help identify vulnerability hotspots. This includes for example data on poverty and nutrition, or incidence of rain-fed agriculture. 
Figure 1 The ORCHID climate risk screening methodology

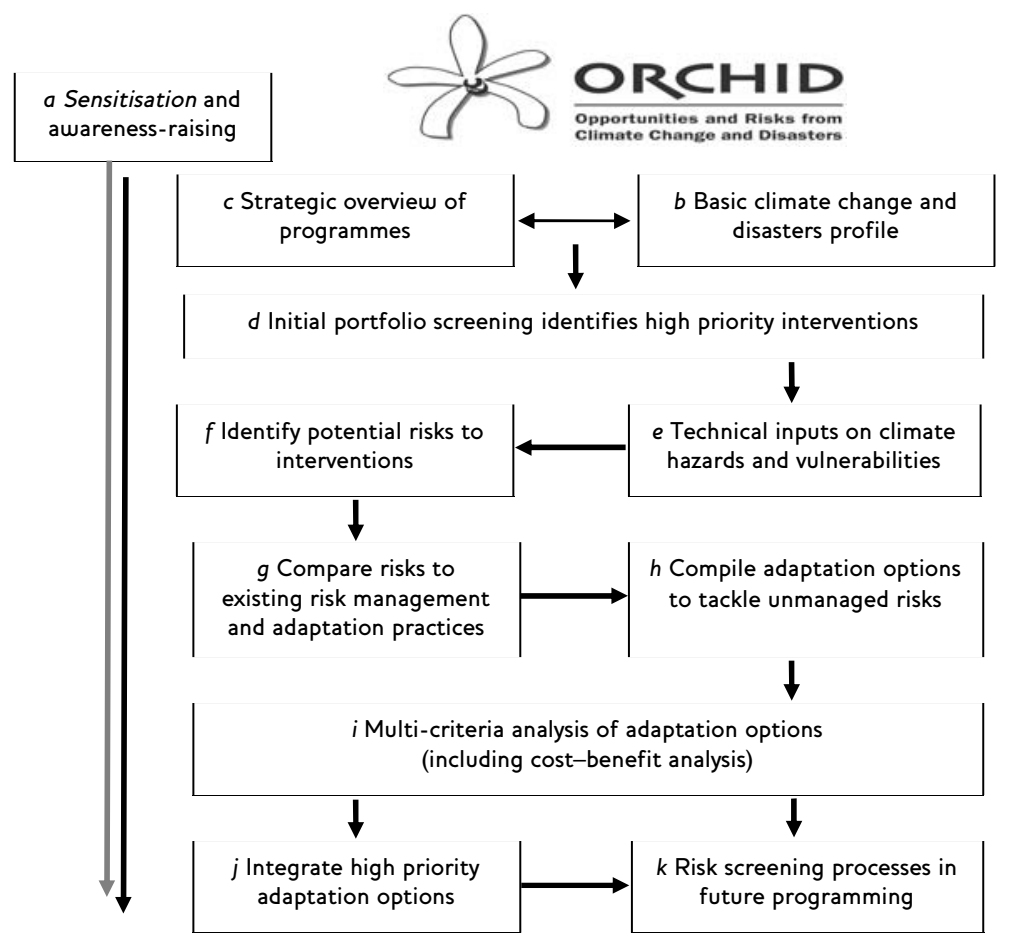

\section{Applying climate risk screening: the ORCHID methodology}

The climate risk management process presented here employs a facilitated process to enable the development cooperation actors to assess current and future climate risks to programmes and to develop adaptation and disaster risk reduction options to manage these risks where necessary. Stressing the potential positive as well as negative impacts of climate change for poverty reduction, the methodology is called ORCHID (Opportunities and Risks of Climate Change and Disasters), and was developed from pilot climate risk screening exercises of the DFID development cooperation portfolios in Bangladesh and India (Tanner et al. 2007a,b). ${ }^{2}$

The steps of the ORCHID methodology are shown schematically in Figure 1. It seeks to establish climate change adaptation as an ongoing process of risk management (see box k) rather than a single discrete output, and emphasises the importance of raising awareness and disseminating knowledge (box a). To do so, it involves the active participation of programme managers and staff in determining risks, in evaluating current risk management and in developing and prioritising adaptation options. This process is guided by a resource person with a broad understanding of development, disaster management and climate change.

After initial awareness raising and sensitisation to climate change issues, the first step in the process compares a summary of climate trends, forecasts and impacts with the portfolio as a whole (see boxes $b$ and $c$ in Figure 1). At the portfolio level, dividing interventions by sector category produces a general picture of the extent to which development interventions are exposed to climate risks ${ }^{3}$ (Agrawala 2005). Low estimates include sectors in more commonly climate-sensitive activities, such as rural livelihoods or water and sanitation programmes through to high estimates including disaster relief and recovery and infectious disease-related health programmes. A snapshot of the DFID-India portfolio in early 2007 (Table 2) suggests that a significant proportion of the portfolio is potentially exposed to climate risks. 
Table 2 Estimated climate risk exposure of the DFID-India portfolio

\begin{tabular}{|c|c|c|c|}
\hline & \multicolumn{3}{|c|}{ Proportion of DFID-I portfolio in climate sensitive sectors (\%) } \\
\hline & Low estimate & Medium estimate & High estimate \\
\hline National programme & 0.3 & 0.6 & 29 \\
\hline Partner state programmes & 50 & 54 & 70 \\
\hline Total DFID-India portfolio & 26 & 28 & 49 \\
\hline
\end{tabular}

Discussions with programme staff around the sensitivity of activities and objectives within individual projects and programmes (hereby referred to as interventions) then determines a set of high priority interventions for which more detailed screening is undertaken (see box $d$ in Figure 1). As well as potential climate risks, there may also be pragmatic reasons for giving particular interventions attention such as strong demand from partners, a past record of climate impacts, or clear opportunities for risk reduction and adaptation.

A more detailed set of technical inputs collated by a resource person is then used as the basis for identifying potential risks to programme objectives and activities. This includes historic climate trends and impacts, latest knowledge on future climate trends, including decadal forecasting techniques more suited to programme time-horizons (Wilby 2007), climate vulnerability assessments where available, and summaries of past economic impacts (see boxes $e$ and $f$ ).

Identified risks are then assessed with programme staff against existing risk management practices and a wide range of potential adaptation options are identified for tackling unmanaged risks and exploiting opportunities for strengthening adaptive capacity (see boxes $g$ and $h$ in Figure 1). These potential options draw on existing experiences and emerging good practice from the disaster risk reduction and adaptation communities. Guided by a resource person, a multi-criteria analysis (MCA) of adaptation options was then performed by programme staff and partners. The MCA process involved choosing a range of decision-making criteria on which to prioritise the range of suggested adaptation options, including coherence with national adaptation priorities (see box i). While not intended as a clear-cut means for determining priorities for follow-up, this process stimulated an important process of discussion and deliberation over possible additional activities for integration into the programme objectives and activities, as well as how to integrate this process into the regular programme cycle (see boxes $j$ and $k$ ).

An example of the results of ORCHID climate risk screening for some of the interventions examined in Bangladesh and India during the pilot exercises are shown in Table 3 (pages 92-3). The table illustrates the 'additionality' of the suggested adaptation options by identifying three scenarios: climate risks without the intervention, how the existing intervention already contributed to adaptation through risk management, and how adding suggested adaptation components enables the programme to address risks more comprehensively.

Both the existing risk management and additional activities reflect the conception of adaptation across a continuum, as introduced elsewhere in this IDS Bulletin (Tanner and Mitchell, this IDS Bulletin 'Entrenchment or Enhancement'; McGray et al. 2007). This includes activities that reinforce vulnerability reduction by addressing its drivers; those building response capacity through planning, monitoring, research and assessment; managing climate risk through infrastructure strengthening, adapting livelihoods strategies, strengthening operations and maintenance activities, and improving disaster preparedness; and moves to tackle climate change impacts such as enhancing flood protection for infrastructure.

As adaptation is a relatively new and emerging area of work, it has been important to build the evidence base regarding the economic cost-effectiveness of adaptation options (Stern 2006). While not feasible for all adaptation options due to time and data requirements, two examples of cost-benefit analysis (CBA) of adaptation options were included in each of the pilot exercises. In Bangladesh, this informed the now more widespread programme of raising homesteads on earthen banks above the regular 
flood-line, and offered an analysis of the costeffectiveness of improving flood protection and drainage for roads and highways. In India, the analysis studied flood protection for urban slum sanitation facilities and rainwater harvesting schemes in schools in drought-prone areas

The uncertainty ranges governing future climate change impacts, and therefore benefits stream through incremental impact reductions of proposed changes limited the cost-benefit analysis exercises to physical infrastructure-based adaptation options. Results of these analyses are presented elsewhere (Tanner et al. 2007a,b), but they are crucial in demonstrating the cost-effectiveness of adaptation options for a range of future climate, cost and benefit scenarios. Even under uncertain future climate scenarios, this analysis strengthens cost-benefit analysis exercises from the disaster risk reduction community suggesting that anticipatory investments to reduce risks can be an efficient use of scarce resources (Venton and Venton 2004; Stern 2006).

\section{Lessons and challenges for pro-poor adaptation}

As a guided stakeholder process, the climate risk screening enabled development agency staff and partners to think through and act on potential climate risks and opportunities. Evaluations revealed that this process enabled programme staff to highlight vulnerable sectors and regions, identify key risks over different timescales, and create opportunities to develop additional activities for strengthening adaptation and disaster risk reduction processes. Undertaking the process raised awareness of the impacts of climate variability and change, and linked adaptation and disaster risk reduction to the poverty reduction context rather than treating them as discrete issues. It also demonstrated existing deficiencies in climate risk management that warrant attention with or without the additionality of climate change impacts. Quantified data on costs and benefits of adaptation options added weight to this argument and therefore to the growing evidence base around the allocation of resources to adaptation and disaster risk reduction.

The lessons and experience of the pilot screening, undertaken as a snapshot of development portfolio activity, also permit reflection on how to integrate such risk assessment processes into the regular programme cycle and ensure coherence with other development cooperation (Gigli and Agrawala 2007) Building climate risk into development assistance requires a more involved and iterative process of dialogue with development partners and embedding into prioritisation, implementation, monitoring and evaluation, and reflection. As developing countries develop their own increasingly advanced adaptation policies and plans, these initial analyses and priorities can inform the future risk management process. Supporting the ability of partner governments to undertake climate risk assessments will be especially crucial in the context of increasing budget support to government programmes and in enabling resource decisions for delivery of adaptation services by the private as well as public sector (Vernon, this IDS Bulletin).

The climate risk screening process outlined in this article also highlights the difficulty of providing adaptation guidance at the strategic level that includes input from stakeholders across scales, including programme beneficiaries. This is important given that adaptation is highly context and location specific (Smit et al. 2000), but also to ensure that they are not developed independently of other development and poverty reduction actions and processes. This implies that climate risk screening at programme level must be followed up in more detail by programme partners, such that climate risks are assessed in the context of the wider range of vulnerabilities and risks faced by poor people.

The greater availability of climate projection data over vulnerability information can lead strategic level exercises to conceptualise adaptation in terms of 'predict and provide', steering the process to technical solutions that deliver an adaptation outcome or product as a palliative managerial fix (Klein et al. 2007). The ORCHID screening pilots suggest that including the best available climate science remains an important driver for contextualising current climate variability. However, the generation of forecasts and impacts information needs greater orientation towards the variety of needs of both programming cycles and poor people (Wilby 2007; Challinor, and Suarez et al., this IDS Bulletin) and that this needs to be matched with far greater attention to vulnerability assessments.

Available climate vulnerability data remains predominantly focused on the nature of hazards and the receiving ecosystems. In contrast, the ability to 


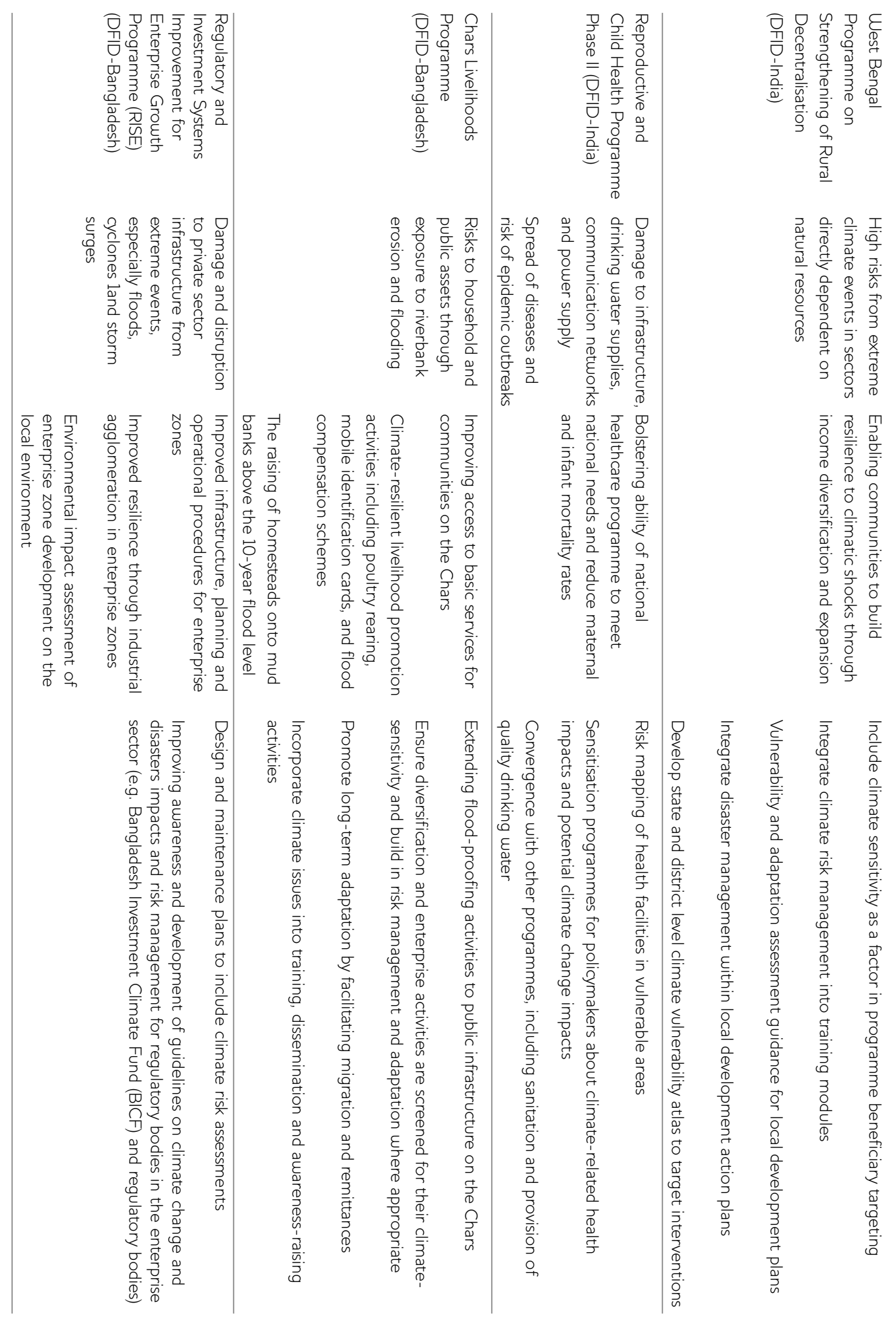

92 Tanner Climate Risk Screening of Development Portfolios and Programmes 
cope with and respond to climate shocks depends on a wide range of factors in relation not only to the nature of shocks but also the characteristics of a population and assets people possess, and the dynamic processes governing exposure, sensitivity and responses to climate impacts (Chambers 1989; O'Brien et al. 2004). There remains an urgent requirement for improved assessments of such social vulnerability to climate shocks and stresses, undertaken in parallel with historic and projected impacts data to permit cross-comparison of datasets and the development of dynamic vulnerability baselines to evaluate progress (Adger 2006; Stephen and Downing 2001; Thomalla et al. 2006; Hedger et al., this IDS Bulletin).

Understanding vulnerability in the context of poverty requires a more process-based conception of adaptation where trial and error, and learning and reflection are key factors. In enabling adaptation that secures poverty reduction outcomes, a process-based approach is more likely to highlight and tackle the underlying causes of vulnerability to climate change and foreground issues of equity and justice.

Methodological debates around adaptation practice in a development context are likely to continue as experience evolves, particularly through development and sharing of adaptation tools and approaches among the development community (OECD 2006; Tanner and Guenther 2007; IISD 2008). Placing the multidimensional livelihood strategies and adaptation needs of poor people at the centre of these efforts will be crucial to sustaining poverty reduction in a changing climate. 


\section{Notes}

1 Fiduciary risk refers to risks where funds are not used for the intended purposes, do not achieve value for money, or are not properly accounted for (DFID 2004).

2 More information and links to reports on ORCHID climate risk screening pilots are available at www.ids.ac.uk/climatechange/orchid. Hybrid versions of the methodology have been tailored for similar climate risk screening exercises in Kenya and China (Tanner et al. 2008). Many thanks to Yvan Biot for support and constructive comments on the ORCHID pilots that have been incorporated in this article.

\section{References}

ADB (2005) Climate Proofing: A Risk-based Approach to Adaptation, Philippines: Asian Development Bank

ADB (African Development Bank); Asian Development Bank; Department for International Development: United Kingdom; DirectorateGeneral for International Cooperation: the Netherlands; Directorate General for Development: European Commission; Federal Ministry for Economic Cooperation and Development: Germany; Organisation for Economic Co-operation and Development; United Nations Development Programme; United Nations Environment Programme; World Bank (2003) Poverty and Climate Change: Reducing the Vulnerability of the Poor Through Adaptation, www.undp.org/energy/povcc.htm (accessed 8 July 2008)

Adger, W.N. (2006) 'Vulnerability', Global Environmental Change 16.1: 268-81

Adger, W.N.; Kelly, P.M. and Ninh, N.H. (eds) (2001) Living with Environmental Change: Social Resilience, Adaptation and Vulnerability in Vietnam, London: Routledge

Agrawala, S. (ed.) (2005) Bridge Over Troubled Waters, Linking Climate Change and Development, Paris: Organisation for Economic Co-operation and Development

Burton, I. and van Aalst, M. (2004) Look Before you Leap: A Risk Management Approach for Incorporating Climate Change Adaptation in World Bank Operations, Washington DC: World Bank

Chambers, R. (1989) 'Editorial Introduction: Vulnerability, Coping and Policy', IDS Bulletin 20.2: $1-7$
3 This approach follows an OECD methodology and operates on the premise that development activities in sectors relating to water resources, infectious diseases, or natural resources are more likely to be affected by present day climate variability and weather extremes, and consequently also by changing climatic conditions. Those relating to financial reform, civil society capacity building, gender equality, human rights or governance reform for example, are much less likely to be directly affected by climatic circumstances (Agrawala 2005).

DFID (2006) Eliminating World Poverty: Making Governance Work for the Poor, White Paper on International Development, London: HMSO

DFID (2004) Managing Fiduciary Risk when Providing Poverty Reduction Budget Support, DFID Briefing, Policy Division Info series, Ref no: PD Info 044, London: Department for International Development

EC (2004) EU Strategy on Climate Change in the Context of Development Cooperation: Action Plan 2004-2008, Brussels: DGE, European Commission

G8 (2008) G8 Hokkaido Toyako Summit Leaders Declaration, Hokkaido Toyako, 8 July, www.g8summit.go.jp/eng/doc/index.html (accessed 13 July 2008)

G8 (2005) Gleneagles Plan of Action - Climate Change, Clean Energy and Sustainable Development, www.britishembassy.gov.uk/Files/kfile/PostG8_Gl eneagles_CCChapeau.pdf (accessed 8 July 2008)

Gigli, S. and Agrawala, S. (2007) Stocktaking of Progress on Integrating Adaptation to Climate Change into Development Co-operation Activities, COM/ENV/EPOC/DCD/DAC (2007) 1/FINAL, Paris: OECD

Hellmuth, M.E.; Moorhead, A.; Thomson, M.C. and Williams, J. (eds) (2007) Climate Risk Management in Africa: Learning from Practice, New York: International Research Institute for Climate and Society (IRI), International Institute for Sustainable Development, Columbia University

IISD (2008) 'Summary of the UNFCCC Expert Group Meeting on Methods and Tools and on Data and Observations under the Nairobi Work Programme', Mexico City, 4-7 March, Earth Negotiations Bulletin 12.355, 10 March, 
www.iisd.ca/download/pdf/enb12355e.pdf (accessed 10 June 2008)

Klein, R.T.J.; Eriksen, S.E.H.; Næss, L.O.; Hammill, A.; Tanner, T.M.; Robledo, C. and O'Brien, K.L. (2007) 'Portfolio Screening to Support the Mainstreaming of Adaptation to Climate Change into Development Assistance', Climatic Change 84.1: 23-44

McGray, H.; Bradley, R. and Hammill, A. (2007) Weathering the Storm: Options for Framing Adaptation and Development, Washington DC: WRI, http://pdf.wri.org/weathering_the_storm.pdf (accessed 14 July 2008)

O’Brien, K.; Eriksen, S.; Schjolden, A. and Nygaard, L.P. (2004) What's in a Word? Conflicting Interpretations of Vulnerability in Climate Change Research, Working Paper, Oslo: Center for International Climate and Environmental Research (CICERO)

OECD (2006) Declaration on Integrating Climate Change Adaptation into Development Co-operation Adopted by Development and Environment Ministers of OECD Member Countries, 4 April, Paris: Organisation for Economic Co-operation and Development

Smit, B.; Burton, I.; Klein, R.J.T. and Wandel, J. (2000) 'An Anatomy of Adaptation to Climate Change and Variability', Climatic Change 45: 223-51

Stephen, L. and Downing, T.E. (2001) 'Getting the Scale Right: A Comparison of Analytical Methods for Vulnerability Assessment and Household Level Targeting', Disasters 25.2: 113-35

Stern, N. (2006) The Economics of Climate Change: The Stern Review, Cambridge: Cambridge University Press

Tanner, T.M. (2008) 'Climate Risk Management and ODA: Linking Disaster Risk Reduction and Climate Change Adaptation through Portfolio Screening', in 'Re-aligning Disaster Risk Reduction and Climate Change Adaptation', Asian Disaster Management News, January-April, Bangkok: ADPC
Tanner, T.M. and Guenther, B. (2007) Sharing Climate Adaptation Tools: Improving Decision-making for Development, Report of Geneva workshop, 11-12 April, IDS, IISD and World Bank, Brighton: IDS

Tanner, T.M.; Xia, J. and Holman, I. (2008) Screening for Climate Change Adaptation: A Process to Assess and Manage the Potential Impact of Climate Change on Development Projects and Programmes in China, Beijing: Institute of Geographic Sciences and Natural Resources Research, Chinese Academy of Sciences

Tanner, T.M.; Hassan, A.; Islam, K.M.N.; Conway, D.; Mechler, R.; Ahmed, A.U. and Alam, M. (2007a) ORCHID: Piloting Climate Risk Screening in DFID Bangladesh, Research Report, Brighton: IDS

Tanner, T.M.; Bhattacharjya ,S.; Kull, D.; Nair, S.; Sarthi, P.P.; Sehgal, M. and Srivastava, S.K. (2007b) ORCHID: Climate Risk Screening in DFID India. Research Report, Brighton: IDS

Thomalla, F.; Downing, T.; Spanger-Siegfried, E.; Han, G. and Rockström, J. (2006) 'Reducing Hazard Vulnerability: Towards a Common Approach Between Disaster Risk Reduction and Climate Adaptation', Disasters 30.1: 39-48

UNDP (2007) Human Development Report 2007/2008 Fighting Climate Change: Human Solidarity in a Divided World, New York: United Nations Development Programme

van Aalst, M. (2006) Managing Climate Risk: Integrating Adaptation into World Bank Group Operations, Global Environment Facility Program, Washington DC: World Bank

Venton, C. and Venton, P. (2004) Disaster Preparedness Programmes in India. A Cost Benefit Analysis, Humanitarian Practice Network Paper 49, London: Overseas Development Institute (ODI)

Wilby, R. (2007) Decadal Forecasting Techniques for Adaptation and Development Planning: A Briefing Document on Available Methods, Constraints, Risks and Opportunities, 17 August, London: Department for International Development (DFID) 